\title{
Coal Bottom Ash as Partial Replacement of Fine Aggregate in Asphaltic Concrete
}

\author{
Mohammed, H., Adebunmi, F.A. and Adewole, B.Z.
}

\begin{abstract}
The effect of coal bottom ash (CBA) on the characteristics of asphaltic concrete was investigated with a view to assess its suitability as a partial replacement of fine aggregate. Coal procured from Lafia-Obi coal mines was burnt in a fixed bed combustor until a sand size residual was produced. The properties of the materials used for the study were characterize using standard procedures. The CBA was introduced in the asphalt mix at an increasing rate of 10, 15, 20 and $25 \%$ content by weight of the fine aggregate and test samples of asphaltic concrete were prepared. The samples were subjected to Marshall stability test. Results showed that the specific gravity and absorption test for granite dust were 2.45 and $0.25 \%$, respectively, while those of the CBA were 2.86 and $0.58 \%$ respectively. The result of stability, flow, bulk density, voids filled in bitumen (VFB), air voids (VA) and voids in mineral aggregate (VMA) of the asphaltic concrete at $0 \%$ CBA were $12.02 \mathrm{kN}, 3.04 \mathrm{~mm}, 2.491 \mathrm{~g} / \mathrm{cm}^{3}, 66.0 \%, 4.3 \%, 12.7 \%$ respectively; while the values at $20 \%$ CBA content were $16.97 \mathrm{kN}, 3.51 \mathrm{~mm}, 2.514 \mathrm{~g} / \mathrm{cm}^{3}, 71.2 \%, 3.4 \%, 11.9 \%$ respectively. The result showed that coal bottom ash in asphaltic mix improved its properties.
\end{abstract}

Keywords: Coal bottom ash, Asphalt concrete, Marshall Test, Volumetric properties, Pavement Strengthening

\section{Introduction}

Flexible pavement gets easily damaged due to various distresses caused by daily increase of traffic loads. This implies a continuous exposure to higher stresses; hence, adequate maintenance is necessary. Higher density of traffic in terms of commercial vehicles, overburdening of trucks, and variation in day by day and occasional temperature rise of the pavement have been responsible for the development of distresses such as raveling, rutting, and fatigue failures of bituminous surfaces [1].

For pavement to serve under these severe conditions for both present and future purposes there must be a continuous search

\footnotetext{
Mohammed, H., Adebunmi, F. A (Department of Civil Engineering, Obafemi Awolowo University, Ile-Ife, Nigeria)

Adewole, B. Z (Department of Mechanical Engineering, Obafemi Awolowo University, Ile-Ife, Nigeria)

Corresponding author: hmesteem@yahoo.com

Phone Number: +234-803-725-2038
}

for improvement in construction practices and more intelligent use of better construction materials [2].

In flexible pavement construction, asphalt concrete is a material that is very important in its construction. Asphalt blends are generally utilized in the outmost layer of road and runway pavements. The blend is made normally out of asphalt cements and aggregate. The design of standard mix for asphalt surfaced pavement, similarly as with the structure of some other construction/engineering materials is to a great extent a matter of choosing and allocating constituent materials to acquire the ideal attributes in the completed asphalt structure [3].

The rising cost and depletion of natural resources used in various highway construction prompted researches on how waste products, such as coal ash and others can be utilized as engineering materials in 
road construction in place of conventional ones. Bottom ash is considered a waste item with couple of commercial uses. It is a byproduct of coal combustion and researches have proven that it may be considered as a reasonable swap for a bit of the aggregate generally utilized in asphalt pavement.

According to research by [4], bottom ash can be used in transportation related works such as dike fill, roadway fill, sub-base, and base courses. Realizing the capability of coal bottom ash to be utilized in civil engineering particularly in roadway building, numerous researchers have considered approaches to change over these waste materials into wealth. The use of asphalt concrete for construction of new roadway requires a great deal of resources. Substitute waste products which reduce cost is desirable, hence this study.

\section{Materials and Methods}

The materials used in this study were bitumen, coarse aggregate, fine aggregate and coal bottom ash. The bitumen used was $60 / 70$ penetration grade. It was obtained from a construction site along Ede-Osogbo road, Osun state. The coarse aggregate consisted of granite aggregate of sizes ranging from 19-4.75 $\mathrm{mm}$. The fine aggregate consisted of granite particles passing $4.75 \mathrm{~mm}$ and retained on $75 \mu \mathrm{m}$ BS sieves.

The coal bottom ash used was produced by burning the coal obtained from Lafia-Obi coal mines, Nasarawa state, Nigeria, in a fixed bed combustor till sand sized residual was obtained. The ash was sieved through $4.75 \mathrm{~mm}-75 \mu \mathrm{m}$ BS sieves and the ash retained on $75 \mu \mathrm{m}$ was used. The properties of the bitumen, aggregates and the coal bottom ash were determined using standard procedures. The mix design proportion consisted of coarse aggregates of $19 \mathrm{~mm}(24 \%), 12.5 \mathrm{~mm}$ $(18 \%)$ and $9.5 \mathrm{~mm}(18 \%)$; fine aggregates of
$4.75 \mathrm{~mm} \mathrm{(5 \% ),} 2.36 \mathrm{~mm} \mathrm{(5 \% )} \mathrm{and} 0.075 \mathrm{~mm}$ $(30 \%)$.

\section{A. Specimen Preparation}

The asphalt concrete samples were prepared in accordance with [5] standard at different bitumen (60/70 pen) contents to obtain the optimum bitumen content (OBC) of $4.93 \%$.

Table 1: Physical Properties of Bitumen

\begin{tabular}{llll}
\hline Property & Test Results & Specification & Test Method \\
\hline $\begin{array}{l}\text { Penetration test } \\
(0.1 \mathrm{~mm})\end{array}$ & 63.03 & $60-70$ & ASTM D-5 \\
$\begin{array}{l}\text { Specific gravity } \\
\left(\mathrm{g} / \mathrm{cm}^{3}\right)\end{array}$ & 1.033 & $1.01-1.06$ & ASTM D-70 \\
$\begin{array}{l}\text { Softening point } \\
\left({ }^{\circ} \mathrm{C}\right)\end{array}$ & 49.5 & $48-56$ & ASTM D-36 \\
\hline
\end{tabular}

Table 2: Physical Properties of Granite Aggregate and Coal Ash

\begin{tabular}{lcc}
\hline Properties & Granite & Coal Ash \\
\hline Aggregate crushing value & 23.6 & 0 \\
Flakiness index (\%) & 24.4 & 0 \\
Water absorption (\%) & 0.25 & 0.58 \\
Specific gravity & 2.45 & 2.86 \\
\hline
\end{tabular}

Table 3: Chemical Composition of Coal Ash

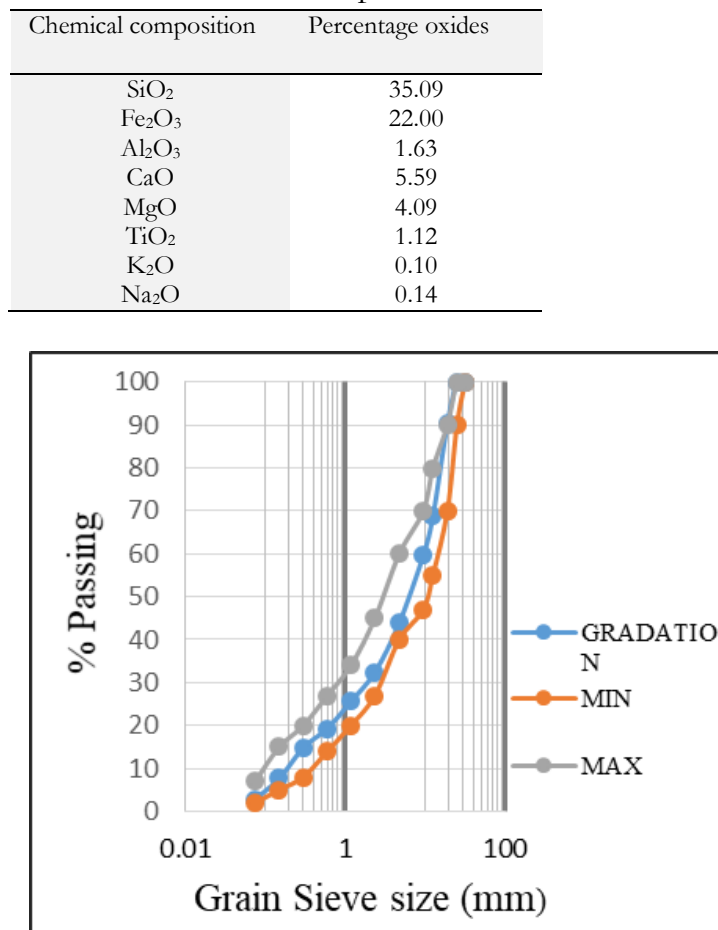

Figure 1: Aggregate grading curve for binder mix design 
This was used to prepare the control mix. Samples were thereafter prepared by replacing portions of granite with coal bottom ash at $10,15,20$ and $25 \%$ by weight of granite dust to produce three samples per bitumen contents.

\section{B. Marshall Stability Test}

Marshall test was carried out and the values of stability, flow, bulk density, voids filled with bitumen (VFB), air voids (VA), and voids in mineral aggregate (VMA) were determined.

\section{Results and Discussion}

\section{A. Physical properties of bitumen}

Table 1 shows the results of the penetration, specific gravity and softening point of bitumen. The values for the penetration, specific gravity and softening point obtained were, $63.03 \mathrm{~mm}, 1.03 \mathrm{~g} / \mathrm{cm}^{3}$ and $49.5{ }^{\circ} \mathrm{C}$ respectively. The results show that the bitumen conforms to all the requirements for asphalt concrete production [6].

\section{B. Physical Properties of Aggregates}

Table 2 shows the results of the aggregate crushing value, flakiness index and water absorption tests. The values obtained are all within allowable limits by FMW\&H specification, [6]. Similar results were also presented by [7].

\section{Chemical Properties of Bottom Ash}

Table 3 shows the chemical composition of the coal bottom ash obtained from particle induced X-ray emission (PIXE). Based on ASTM standards, the major constituents of coal ash are silica $\left(\mathrm{SiO}_{2}\right)$, ferric oxide $\left(\mathrm{Fe}_{2} \mathrm{O}_{3}\right)$ and calcium oxide $(\mathrm{CaO})$. These oxides are typical constituents of fine aggregates.

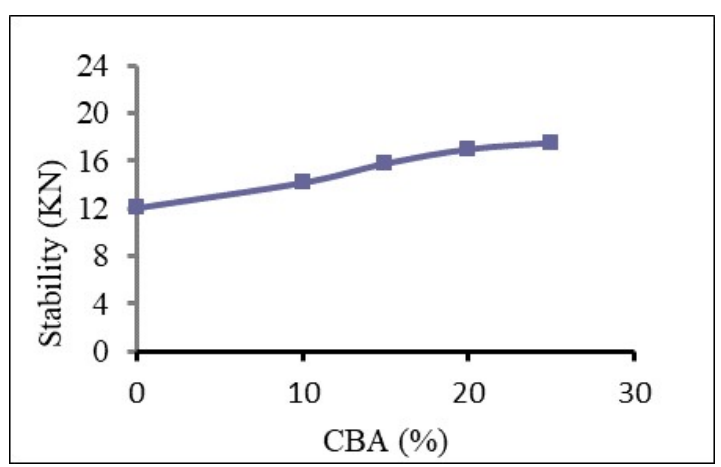

Figure 2: Relationship between stability and coal ash

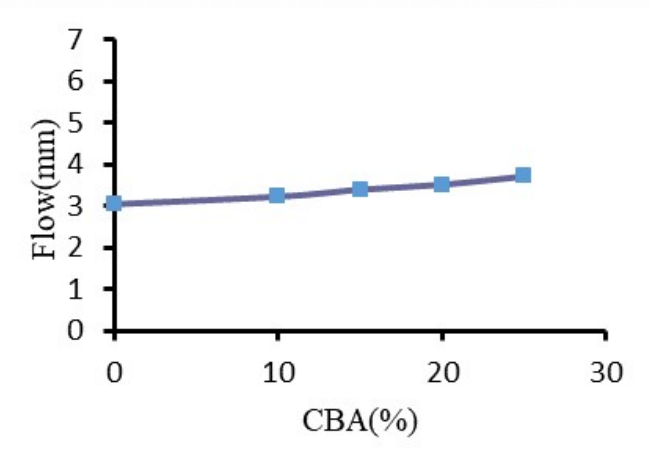

Figure 3: Relationship between flow and coal ash

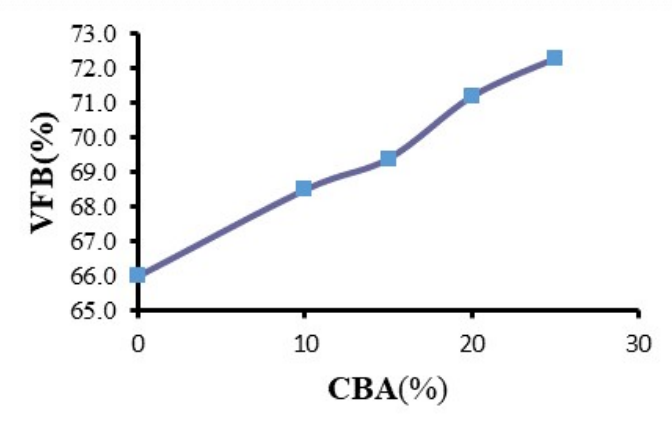

Figure 4: Effect of coal ash on VFB

\section{Aggregate Gradation}

Figure 1 shows the aggregate gradation curve. The curve shows that the blended mix of all selected aggregates fall within the standard specified by the Federal Ministry of Works and Housing [6] for binder course mix design. 


\section{E. Effects of coal ash on Marshall Properties of asphalt concrete}

\section{i. Stability}

Figure 2 shows the relationship between stability and coal ash for all the percentages considered. It is observed that there is a linear relationship between stability obtained from the coal ash added. The stability result showed that all the percentages of Coal Ash were above the control mix. This could be attributed to the specific gravity of Coal Ash as well as the increase in internal friction within the aggregate [8].

\section{ii. Flow}

The relationship between flow and coal ash is presented in Figure 3. It was observed that as the percentage of coal ash increases, likewise an increase in flow. The introduction of coal bottom ash reduced the voids within the aggregate, due to its high specific gravity. This led to the increase in the flow of bitumen in the mix hence, better flexibility of asphalt concrete [8].

\section{iii. Voids filled with Bitumen (VFB)}

Figure 4 shows the relationship between voids filled with bitumen and coal ash. An increase in VFB was observed with increase in $\mathrm{CBA}$ percentages. Higher CBA content results in lower air voids (AV). The relationship between VFB and air voids is inversely proportional and hence as air voids decreases, VFB gradually increases. The result indicates that there is more bitumen in the mix as the coal bottom ash is added. Similar result was observed by [9].

\section{iv. Voids in Mineral Aggregate (VMA)}

Figure 5 shows the relationship between voids in mineral aggregate and $\mathrm{CBA}$ percentages. It is observed that there is a decrease in VMA as CBA increases from $0 \%$ to $25 \%$. [9] averred that higher binder content results in lower air voids (AV) and voids in mineral aggregate (VMA). The addition of CBA in the asphalt mix caused a reduction in the pores of aggregate particles thereby creating less space within the aggregates. Hence a decrease in VMA.

\section{v. Air Void (AV)}

Figure 6 shows the relationship between air void and CBA percentage. A decrease in air

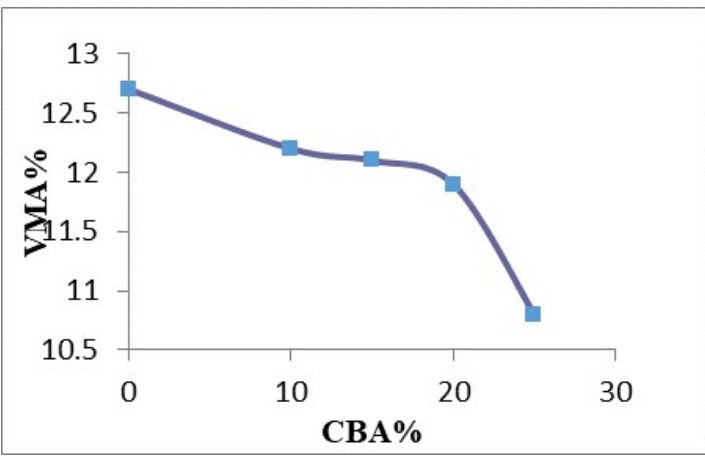

Figure 5: Relationship between VMA and coal Ash

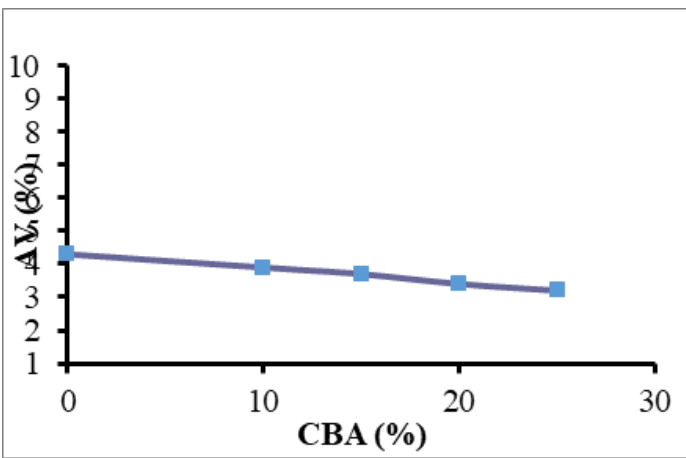

Figure 6: Relationship between air voids and coal ash

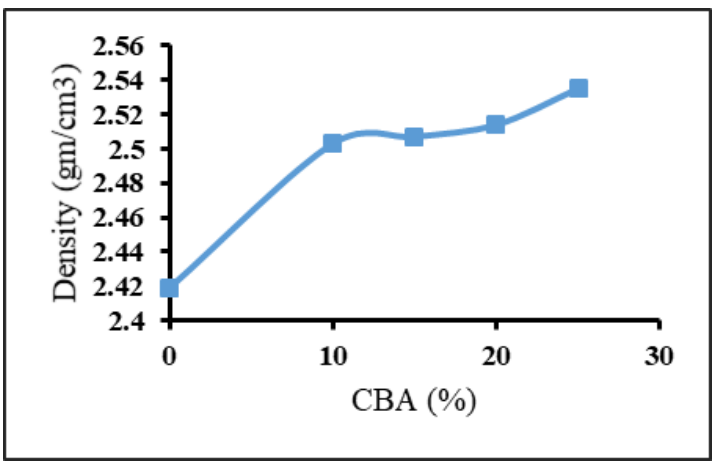

Figure 7: Relationship between bulk density and 
void was observed with increase in CBA percentages from 0 to $25 \%$. The introduction of coal ash reduced air voids because coal ash is denser due to its high specific gravity. The range of air voids lies between 3.2 and $4.3 \%$ which correspond with FMW\&H specification for binder course. The optimum air voids of $3.4 \%$ was obtained at $20 \% \mathrm{CBA}$ content.

\section{vi. Density}

Figure 7 shows the graph of bulk density against CBA percentage. It is observed that the bulk density of asphalt concrete increases as the coal bottom ash content increases. The bulk density of asphalt concrete was higher due to high specific gravity CBA.

\section{Conclusion}

The application of coal ash as a partial replacement of fine aggregate in asphalt concrete binder course showed improvement in its Marshall properties. Based on the result of marshal analysis, the proportion of asphalt mixes with bottom ash shows that all samples containing coal bottom ash display values within specification for all marshal stability parameters in the mix. The result further showed that coal bottom ash can be used as a partial replacement of fine aggregate in asphalt concrete to improve its Marshall parameters.

\section{References}

[1] Tomar, R., Jain, R.K. and Kostha, M.K. "Effects of Fillers on Bituminous Paving Mixes", International Journal of Engineering Research, Science and Technology, vol. 2, no. 4, 2013, pp. 2319-5991.

[2] Roberts, F.L., Kandhal, P.S., Brown, E.R., Lee, D.Y. and Kennedy, T.W. "Hot Mix Asphalt Materials, Mixture Design, and Construction", National Asphalt Pavement Association Education Foundation, Lanham, MD,
Transportation Research Board, Washington, DC, 1996.

[3] Nathem, A.H. "A Study on the Effect of Filler Type and Content on Hot Asphalt Concrete Mixtures Properties", Unpublished M.Sc. Dissertation, College of engineering/civil engineering department, Mosul University, 2013.

[4] Pandeline, D.A., Cosentino, P.J., Kalajian, E.H. and Chavez, M.F. 'A Study on the Shear and Deformation Characteristics of Municipal Waste Combustor Bottom Ash for Highway Applications", Transport Reseach Record, vol. 1577, no. 1, 1997, pp. 101-108.

[5] American Society for Testing and Materials, "Standard Test Method for Penetration of Bituminous Materials", ASTM D1559, ASTM International, West Conshohocken, PA, United States, 1997.

[6] Federal Ministry of Works and Housing, "General Specifications for Roads and Bridges", Federal Higbway Department, Lagos, Nigeria, vol. 11, 1997.

[7] Brennan, M.J. and O'Flaherty, C.A. "Highway Materials used in Road Pavement", Fourth Edition, Butterworth and Heinemann, Oxford, United Kingdom, 2002, pp. 118-162.

[8] Gunalaan, V.A. "Study on the Performance on Coal Bottom Ash in Hot Mix Asphalt", Unpublished Dissertation, Faculty of Engineering and Built Environment, Tunku Abdul Rahman University College, Malaysia, 2013.

[9] Kurtis, K. "Asphalt and Asphalt Concrete", http://people.ce.gatech.edu/kk92/asplarger.pdf, Retrieved on 28th April, 2013. 